R. Italianística, São Paulo, ano I, n* 1, p. 83-90, 1993.

\title{
O MORTUÁRIO NA FICÇÃO DE PIER PAOLO PASOLINI
}

\author{
Aurora Fornoni Bernardini*
}

Resumo: O presente texto visa levantar biográfica e psicanaliticamente possíveis fontes do mortuário na fiçāo de Pasolini e discuti-las partindo de exemplos retirados basicamente de Ragazzi di vila e Una vita violenta.

Palavras-chave: mortúírio, ficção, Pasolini, Freud, Dostoiévski.

Em 25 de setembro de 1987, o cineasta italiano Marco Bellocchio estava respondendo às perguntas dos interessados no Auditório do jornal Folha de S. Paulo quando alguém da platéia perguntou-lhe o que ele achava dos filmes de Pasolini. A resposta foi extremamente direta: "Como Pasolini é um cineasta homossexual, seus filmes são mortuários. E o mortuário não é o que me alrai."

O que me surpreendeu não foi a radicalidade da opinião que, expromptu, cortava tantos outros aspectos da cinematografia pasoliniana, mas justamente a natureza do acoplamento expressa na observaçāo, que vinha ecoando uma "descoberta" (chamemo-la assim) que eu fizera pouco antes. Refere-se a Alberto Arbasino. de quem lera com total admiração o enlevante trabalho jornalístico Truns-Pacific Express (1981). relato de 10 viagens a 10 países do Oriente e a melhor apreciação crítica possível (na época assim pareceu-me) de Carlo Emilio Gadda; com admiração, apenas, Fratelli d'Italia (1976) (houve quem considerasse a obra um supermercado cultural) e com total desilusão dois romances: La narcisata e Specchio delle mie brame. 0 porquê dessa desilusão tora o tom exageradamente "mortuário", aparentemente insuspeito no jornalista. mas que agora, no romancista, tornava-se elemento dominante.

Lembrando-me de um artigo que lera no Jornal da Tarde e que também me impressionara (1977), de autoria do crítico Leo Gilson Ribeiro,

\footnotetext{
Professora de Lingua e Literalura Russa, junto au Departamento de Línguas Orientais, e de Teoria Literária e Literaturn Comparada, junto ao Departamento de Teoria Literária e Literatura Comparada da Faculdade de Filosofia, Letras e Ciências Humanas, USP.
} 
BERnARDini, Aurora Fornoni. O mortuário na ficção de Pier Paolo Pasolini.

onde se dizia que - como com as grandes hordas de coelhos que, na Austrália, se atiravam ao mar, para morrer, por instinto, quando falta comida para tantos - a natureza, atribuindo aos homossexuais o papel de não-reprodutores e multiplicando-os, em tão grande número, estaria, quem sabe, moderando, entre os humanos, o excesso de reproduçāo, perguntei-me, na época, se mesmo psiquicamente o instinto dominante neles não seria a pulsão da morte: grandioso exemplo de sujeição ao biológico, mas muito perigoso e talvez injusto, enquanto generalização, concluíra eu.

Enfim, deixara o caso pendente. Quando o heideggariano Castoriadis esteve em São Paulo, na década de 80, convidado pelo curso de pós-graduação em psicologia do Sedes Sapientiae a um debate com o marxista Lefèvre, eu já sabia que realmente cada ser humano, seja ele homossexual, bissexual ou heterossexual, tende, em suas gradações e matizes, ou para o pólo da vida ou para o pólo da morte e deduzira que os heideggarianos, enquanto não interventores na realidade com um projeto, qualquer que fosse o destino do mundo, eram os filósofos mortuários do debate. Agora essa afirmação de Bellocchio vinha reacender a questão e eu me propus procurar em Pasolini a prova da tese de Bellocchio. "Neanche a farlo apposta", diriam os italianos, é o próprio Pasolini que encaminha os críticos nesse sentido.

Uma de suas primeiras recordações (de quando ele tinha 3 anos e meio e vivia em Belluno com o pai, tenente de infantaria, e a mãe, prestes a dar à luz o segundogênito) é justamente de um "desesperado amor sexual" pela genitora. "Mi sono dunque trovato nella necessità fisica di 'nominare' quel sentimento e, nel mio stato di parlante solamente vocale... ho inventato un termine, lo ricordo perfettamente: TETA VELETA" (Invito alla lettura, p.22).

Num ensaio de 65 ("Dal laboratorio: appunti en poète per una linguistica marxista", em Empirismo eretico), ele explica a palavra TETA pelo grego TETIS (sexo), que Gianfranco Contini lhe disse ser um reminder (uma coisa que recorda outra), um fenômeno lingüístico típico da pré-história de alguém. Do amor pela mãe à vontade de matar o pai, "passional, sensual, violento" (cf. Ritratti su misura), militar, conformista etc., é só um passo a mais no consagrado esquema freudiano do homossexualismo.

"Il difficile rapporto con il padre si fa sempre più sofferto attraverso i nodi di vita di Pasolini approfondendo sempre più quei caratteri di estraneità e incomprensione dopo la pubblicazione di Poesie a Casarsa..." (Invito alla lettura, p. 42). 
"Il contrasto era feroce: se uno si ammalasse di cancro e poi guarisse avrebbe probabilmente di quella malattia lo stesso ricordo che ho io di quegli anni..." (Ritratti su misura, p. 31).

"Fuggii a Roma con mia madre, come in un romanzo. Mio padre ci raggiunse (...). E mio padre sempre là, in attesa, solo nella povera cucinetta coi gomiti sul tavolo e la faccia contro i pugni, immobile, cattivo, dolorante riempiva lo spazio del piccolo vano con la grandezza che hanno i corpi morti..." (Idem, p. 36).

"Ma la mia vita nella mia casa era sempre la stessa, sempre uguale alla morte. Mio padre soffriva e ci faceva soffrire... Una notte tornai a casa appena in tempo per vederlo 'morire'" (Idem, p. 37).

Sem recorrer às tranches óbvias de sua vida, leiam-se, quanto ao parricídio e ao castigo, as duas resenhas muito sintomáticas que Pasolini escreveu sobre Dostoiévski, "Crime e Castigo" (janeiro de 74) e "Os irmãos Karamazov" (setembro de 74), em Descrizioni di descrizioni.

Na primeira, Pasolini encontra, na morte da velha usuária por parte de Raskólnikov, a morte da mãe-ruim, mãe-dragão (a mãe-pai), e na morte da irmã da velha, a da própria irmã de Raskólnikov - morte metafórica, pois as mesmas logo logo chegariam a S. Petersburgo, vindas da aldeia natal.

Na segunda também, há um desdobramento: os pais mortos na família Karamazov são dois, não um. O pai natural, morto não se sabe por quem, e o criado que fizera suas vezes, supostamente assassinado por Dimitri, que carrega a culpa ou, melhor, conforme Freud, a quem Pasolini remete, anseia pelo castigo: "Dostoiévski, ricorrendo così a un trucco che non ha uguale in un altro luogo delle sue intere opere... ci mette dei puntini. Lo passa, cioè, sotto silenzio, lo rimuove: non lo vuol far sapere e forse non lo vuol sapere lui stesso. In questi puntini c'è tutto Freud!" (p. 377).

E o que diz Freud em "Dostoiévski e o parricídio", a que Pasolini remete, na referida resenha? (Dostoiévski, como se sabe, era epilético, e, como se sabe, não só não se dava com o pai, de quem a mãe era vítima, mas presenciou sua morte violenta, por parte dos servos revoltados, e guardou disso um trauma ìndelével).

"É acertado distinguir entre a epilepsia orgânica e a epilepsia 'afetiva' No primeiro caso, a vida anímica sofre uma perturbação alheia a ela e procedente do exterior; no segundo a perturbação é uma manifestação da própria vida anímica" (p. 1138). 
BERNARDINI, Aurora Fornoni. O mortuário na ficçăo de Pier Paolo Pasolini.

"Conhecemos o sentido e a intenção dos ataques epiléticos que mimam a morte. Supōem a identificação com um morto, com uma pessoa que já morreu ou da qual se deseja a morte. Este último caso é o mais importante. $O$ ataque tem então 0 valor de um castigo. A psicanálise afirma que o outro é, regularmente, para o menino, seu próprio pai. $O$ ataque, chamado histérico, é, portanto, um autocastigo pelo desejo de morte contra o pai odiado.

O parricídio é, segundo interpretação já conhecida, o crime capital e primordial, tanto da Humanidade como do Indivíduo. Desde logo, é a fonte principal do sentimento de culpa, mesmo que não seja a única, pois as investigaçōes não puderam determinar com segurança a origem psíquica da culpa e da necessidade de resgatá-la. A situação psicológica é complicada e precisa de esclarecimentos" (p. 1139).

"A homogeneidade dos sintomas exteriorizados por ocasião do ataque epilético parece demandar uma interpretação funcional, como se tivesse constituído, orgânica e previamente, um mecanismo de derivação anormal dos instintos, mecanismo este ao qual se recorreria nas mais diversas circunstâncias: tanto por ocasião de perturbações da atividade cerebral, por uma grave enfermidade, como ante um domínio insuficiente da economia psíquica. Através desta dualidade suspeitamos a identidade de mecanismo de derivação dos instintos existentes no fundo. Este mecanismo pode ser semelhante aos processos sexuais toxicamente motivados em seu fundo. Os médicos mais antigos já diziam que o coito era uma pequena epilepsia, reconhecendo assim na relação sexual a mitigação e a adaptação da descarga epilética dos estímulos. A 'reação epilética', termo com que podemos designar esse conjunto, se põe indiscutivelmente à disposição da neurose, cuja essência consiste em derivar pelo caminho somático aquelas magnitudes que lhe é impossível manejar psiquicamente" (p. 1138).

Não consta que Pier Paolo Pasolini tenha sido epilético. Consta porém, indiscutivelmente, que em sua atribulada vida o ato sexual, "o mais belo da vida" (cf. Le belle bandiere, p. 191: "Magari il solito punto scuro del codice sarà quello di fare di tutte le erbe un fascio e di abbracciare sotto l'osceno termine di 'atti osceni' anche quello che, nel migliore dei casi, diciamolo francamente, è il più bell'atto del mondo"), no dizer de Pasolini, a "pequena epilepsia", no dizer dos médicos e de Freud, tenha sido fonte contínua e inesgotável de culpa, castigo, dissociação e... de sua própria morte... 
R. Italianística, São Paulo, ano I, n² 1, p. 83-.90, 1993.

Aqui está caracterizada então, mesmo que esquematicamente, a etiologia da pulsão da morte em Pasolini.

Vejamos, agora, como o mortuário se manifesta em sua narrativa.

Muito bem, se na ensaística ou na publicística, como aconteceria com Arbasino, "a paixão pela vida" que Pier Paolo Pasolini sente tão intensamente não é basicamente funérea, mas em seu arrojo e "spennacchiata" coragem, muitas vezes vitalista e envolvente, vejamos o que ocorre com seus romances mais famosos - Ragazzi di vita e Una vita violenta.

À parte o fato de o primeiro terminar com Genesio que se afoga, e o segundo com Tommaso que cospe sangue, e à parte o fato de Tolstói afirmar que qualquer homem, desde que aprenda a pensar, só pode pensar na morte, dei-me ao trabalho de levantar nas páginas dos dois romances alguns momentos em que a morte é anunciada por exclamações, prenunciada por metáforas ou contemplada por expressōes consagradas do jargão romano. Eis aqui anotadas algumas seqüências desses momentos escolhidos por capítulos ou por episódios:

\section{Ragazzi di vita}

I seqüência:

p. 9 - Descrição da paisagem mortuária: "Scarpate putride e bruciate"

p. 11 - Descrição de um cego

p. 14 - Descrição de Horácio. Ênfase nas metonímias "gamba paralitica" e "faccia chiazzata di sangue"

p. 14 - Descrição da ambiência: "Era l'una e mezza e a Roma non c'era che il sole..."

p. 15 - Descrição do Tibre purulento: "E il Tevere scorreva giallo..."

p. 15 - "Era un verminaio..."

p. 16/17/18 - Exuberância das exclamaçōes em jargão: "Li mortacci tua e de tu nonno", "A li mortacci", "Li mortacci sua", "All'anima de li mortacci vostra", que, de agora em diante, por constelarem continuamente as páginas da obra, não serão mais assinaladas.

p. 24 - Descrição da andorinha que está afogando: "Era così bello vedella che se moriva"

p. 31 - Recorrência: uccidere/morire/1'avevamo ammazzà

p. 32 - Descrição da morte de duas prostitutas: "due zoccole bruciate..."

p. 40 - "Facchino de mattatoio"

p. 50 - "Son crollate le scuole..."

p. 51 - Descrição: "Fu portato a spirare in una cameretta apposita..."

p. 53 - "Ai morti erano stati fatti i funerali" 
BERNARDINI, Aurora Fornoni. O mortuário na fiç̧ão de Pier Paolo Pasolini.

p. 54 - Descrição-alusão: "Lo sai chi sta a morì..." (Marcello)

p. 56 - Morte da mãe de Riccetto

p. 57 - "Allora devo proprio morì" (Marcello)

(Fim de episódio-capítulo)

II seqüência:

p. 144-150 - Descrição de ambiência

p. 171 - "ammazza er cane"

p. 172 - Descrição funérea da luta entre cães

p. 182 - Descrição das etapas da queima de Piattoletta

p. 189 - Bagalone digiuno e tubercoloso (descrição)

p. 189 - "Una ragazza morta accanto al letto della pazza"

p. 190-191 - Descrição da mãe de Bagalone "fatturata"

p. 192 - "morire di colpo"

p. 202 - "piscia-acqua" etc. (descrição)

p. 205 - "giovincelli pronti a vendersi" (descrição)

p. 213 - "Corpi sanguinanti e penne di pollo"

Alvaro, sem braço e cegado (descrição)

p. 217 - Sexo e bordel (descrição)

p. 225 - "Sorella: m'ammazzo, m'ammazzo..."

p. 227 - Episódio de Alduccio (faca, ameaça, mãe)

p. 234 - Descrição do rio-esgoto

p. 235 - "Quando semo grandi ammazzamo nostro padre"

p. 241 - "Bagalone si sente male" (descrição)

p. 244 - "Lanzetta ha ammazzato il tassinaro" (descrição)

p. 245 - "È una vittima..."

p. 247 - "Le piattole arrosto..."

p. 253 - Morte de Genesio (descrição)

(Fim de episódio-capítulo)

\section{Una vita violenta}

I seqüência:

p. 10 - "Strillandosi i morti"

p. 11 - "Una fila di forche di impiccati"

p. 13 - Cloaca del policlinico (descrição)

p. 25 - Descrição recorrente de cães vitimizados.

p. 24 - "Una nuvola fitta fitta di campi pidocchiosi"

II seqüência: 
BERnARDINI, Aurora Fornoni. O mortuário ma fiç̧ăo de Pier Paolo Pasolini.

p. 73 - "la comare all'obitorio" (descrição)

p. 80 - Mão e pé de Lello massacrados (descrição)

p. 98 - "Ti giuro per mia madre morta"

p. 110 - In casa Cagone aveva il morto

p.129 - Criança recém-nascida: "li mortacci tua!"

p. 135 - "Il matto era morto"

p. 145 - "Da quando mio padre mi è morto..."

p. 160 - Descrição funérea magistral

p. 166 - "A me nun me li dì li morti..."

p. 167 - A faca (descrição)

p. 174 - "Tito e Toto avevano stirato le gambe" (descrição)

p. 187 - "Mannaggia la morte" (descrição)

III seqüência:

p. 220 a 228 - Seqüência do sonho, naturalmente funéreo

p.232 - "Don don... già morti, sepolti, anime sperdute..."

p. 233 - "Avvisava che qualcuno aveva tirato le gambe"

p. 234 - A morte (descrição)

p. 239 - Funerais de Bernardini

p. 266 - Cagone se enforca

p. 282 - Metáfora funérea recorrente: luz/vermes

Não me parece seja preciso exemplificar ulteriormente o "mortuário" de Pasolini romancista, mortuário este que, conforme verificamos, também aparece na maior parte de sua poesia. Cabe porém um comentário final, no meu entender, imprescindível. Enquanto na ficção de Alberto Arbasino o tom mortuário soou-me artificial, desafinado (não é este o lugar de analisar 0 porquê) - daí ter-me ele desagradado tanto -, na fiç̧ão de Pasolini ele é co-natural ao tema, se assim pode-se dizer, e é resultado da "contaminação" tema/autor/linguagem/leitor que Tolstói considerava condição sine qua non da eficácia literária.

\section{BIBLIOGRAFIA}

ARBASINO, Alberto. Fratelli d'Italia. Torino, Einaudi, 1976.

ARBASINO, Alberto. Specchio delle mie brame. Torino, Einaudi, 1975.

ARBASINO, Alberto. Trans-Pacific Express. Milano, Garzanti, 1981. 
BernardinI, Aurora Fornoni. O mortuário na ficçāo de Pier Paolo Pasolini.

FREUD, Sigmund. Obras Completas. Madrid, Editorial Bibiioteca Nueva, 1968, v. III. MANNINO, Vincenzo. Invito alla lettura di Pasolini. Milano, Mursia, 1977. PASOLINI, Pier Paolo. Descrizioni di descrizioni. Torino, Einaudi, 1979. PASOLINI, Pier Paolo. Empirismo eretico. Milano, Garzanti, 1972. PASOLINI, Pier Paolo. Ragazzi di vita. Milano, Garzanti, 1976.

PASOLINI, Pier Paolo. Ritratti su misura. Venezia, Sodalizio del libro, 1960. PASOLINI, Pier Paolo. Una vita violenta. Milano, Garzanti, 1959.

Abstract: This text intends to discuss biographical and psychanalitical sources of the mortuary in P.P.Pasolini from examples selected from The Ragazzi and $A$ violent life.

Key-words: mortuary, fiction, Pasolini, Freud, Dostoievsky. 